\title{
PENGEMBANGAN E-LEARNING BERBASIS WEB DI SMK PASIM PLUS KOTA SUKABUMI
}

\author{
Willani Oktaviyani ${ }^{1}$, Luthpi Saepuloh ${ }^{2}$, Heni Wulandari ${ }^{3}$ \\ Pendidikan Teknologi Informasi Universitas Muhammadiyah Sukabumi \\ Jl. R. Syamsudin, S.H. No. 50, Cikole, Kec. Cikole, Kota Sukabumi \\ willanioktaviyani@ummi.ac.id
}

\begin{abstract}
Abstrak: Penelitian ini bertujuan untuk menghasilkan produk berupa website e-learning dengan nama domain https://moodle.pasimlearning.com yang layak digunakan untuk proses pembelajaran jarak jauh. Jenis penelitian yang digunakan adalah penelitian dan pengembangan dengan mengadopsi model pengembangan Borg \& Gall. Metode pengumpulan data yang digunakan ialah kuesioner dan wawancara, dengan menggunakan intstrumen pengumpulan data berupa lembar validasi yang teridiri atas lembar validasi ahli media, lembar validasi ahli materi, dan angket respon peserta didik. Partisipan penelitian adalah peserta didik kelas XI OTKP 1 SMK Pasim Plus Sukabumi sejumlah 5 orang di uji coba skala kecil dan 20 orang di uji coba skala besar. Hasil akhir penilaian pada produk yang dikembangkan menunjukkan rerata 4,4 dari skala 5 (Sangat Layak) dari ahli media, rerata 5 dari skala 5 (Sangat Layak) dari ahli materi, dan rerata 4,1 dari skala 5 (Layak) dari 5 peserta didik uji coba kecil, serta rerata 4,6 dari skala 5 (Sangat Layak) dari 20 peserta didik uji coba besar. Dengan demikian, https://moodle.pasimlearning.com sangat layak digunakan sebagai media dalam proses pembelajaran jarak jauh.
\end{abstract}

Kata Kunci: Media, E-Learning, Moodle

\begin{abstract}
This study aims to produce a product in the form of an e-learning website with the domain name https://moodle.pasimlearning.com which is suitable for the distance learning process. The type of research used is research and development by adopting the Borg \& Gall development model. Data collection methods used were questionnaires and interviews, using data collection instruments in the form of a validation sheet consisting of a media expert validation sheet, a material expert validation sheet, and a student response questionnaire. The research participants were 5 students of class XI OTKP 1 SMK Pasim Plus Sukabumi in the small-scale trial and 20 in the large-scale trial. The final result of the assessment on the product developed shows a mean of 4.4 out of a scale of 5 (Very Eligible) from media experts, a mean of 5 out of a scale of 5 (Very Feasible) from a material expert, and a mean of 4.1 out of a scale of 5 (Feasible) from 5 participants small trial students, as well as a mean of 4.6 from a scale of 5 (Very Eligible) from 20 students in the large trial. Thus, https://moodle.pasimlearning.com is very suitable to be used as a medium in the distance learning process.
\end{abstract}

Keywords: Media, E-Learning, Moodle

History :

Submit tgl 14 Agustus 2020, revisi 17 Agustus 2020, diterima 17 Agustus 2020 


\section{PENDAHULUAN}

Tak dapat dipungkiri, perkembangan teknologi informasi dan komunikasi melaju dengan begitu pesatnya. Dampaknya, sebagaimana tadinya tujuan teknologi dikembangkan, adalah kemudahan dan kemurahan dalam berbagai aktifitas manusia. Namun, apabila manusia sendiri tak mampu mengiri alur permainan yang dihadirkan teknologi, sekurang-kurangnya hal tersebut justru dapat menjadi bumerang bagi dirinya.

Seperti ditulis dalam jurnal Prosiding SEMATEKSOS 3 "Strategi Pembangunan Nasional MenghadapiRevolusiIndustri 4.0":

"Era ini akan mendisrupsi berbagai aktivitas manusia dalam berbagai bidang, tidak hanya dalam bidang teknologi saja, namun juga bidang yang lain seperti ekonomi, sosial, dan politik. Di sektor ekonomi telah terlihat bagaimana sektor jasa transportasi dari kehadiran taksi dan ojek daring. Hal yang sama juga terjadi di bidang sosial dan politik. Interaksi sosial pun menjadi tanpa batas (unlimited), karena kemudahan akses internet dan teknologi. Dalam bidang politik, melalui kemudahan akses digital, perilaku masyarakat pun bergeser. Aksi politik kini dapat dihimpun melalui gerakangerakan berbasis media sosial dengan mengusung ideologi politik tertentu."(Prasetyo \& Trisyanti, 2019)

Demikian halnya dengan sektor pendidikan, belajar dan pembelajaran yang ada di dalamnya terancam terdegradasi apabila pendidik tak mampu dan tak mau mengikuti alur perkembangan teknologi. Dalam penelitian yang dimuat dalam jurnal Seminar Nasional Vokasi dan Teknologi disampaikan:

"Jika peran pendidik masih mempertahankan sebagai penyampai pengetahuan, maka mereka akan kehilangan peran seiring dengan perkembamgan teknologi dan perubahan metode pembelajarannya. Kondisi tersebut harus diatasi dengan menambah kompetensi pendidik yang mendukung pengetahuan untuk eksplorasi dan penciptaan melalui pembelajaran mandiri.”(Triyono, 2017)

Sekaitan dengan itu, Astuti dkk dalam jurnal Seminar Nasional Pascasarjana 2019 juga mengatakan bahwa:

"Garda terdepan pendidikan adalah guru. Namun di Era Revolusi Industri peran guru bergeser dengan hadirnya Google Asistence. Diperlukan strategi pembelajaran yang menarik sehingga guru memiliki peranan sebagaimana mestinya.”(Astuti et al., 2019)

Dari ketiga pernyataan dalam masingmasing penelitian tersebut dapat diambil kesimpulan bahwa pendidikan, dalam hal ini proses belajar dan pembelajaran, harus dapat menyesuaikan posisinya agar tak lantas terdegradasi oleh perkembangan teknologi. Sebab bagaimanapun, peran pendidik dalam membentuk dan mempersiapkan peserta didik agar menjadi manusia utuh dan siap mengahadapi dunia luar tak dapat digantikan oleh secanggih apapun teknologi yag ada. Sentuhan manusia masih sangat dan akan selalu peserta didik butuhkan dalam proses penggalian dan penemuan kualitas dirinya.

Selama melakukan magang di SMK Pasim Plus Kota Sukabumi, peneliti mengkuti, mengamati, dan merasakan langsung bagaimana proses belajar dan pembelajaran berlasngusng di sana,khususnya pada mata pelajaran Simulasi dan Komunikasi Digital di kelas X OTKP. Di luar jam praktik, proses pembelajarn masih dilakukan dengan cara konvensional memfaatkan buku dan papan tulis dalam 
ruang kelas. Sementara jika dilanda kebosanan, peserta didik akan sibuk dengan hiburan yang ada dalam gawainya. Padahal jika dilihat dari fasilitas yang ada, sangat mungkin untuk proses belajar dan pembelajaran dilakukan dengan basis teknologi, termasuk di dalamnya salah satu aturan sekolah yang tidak membatasi akses terhadap gawai dan internet oleh peserta didik, menjadikannya media dalam proses belajar dan pembelajaran sangat memungkinkan. Seperti disebutkan dalam bukunya yang berjudul Media Komunikasi Pembelajaran, "media pembelajaran adalah segala sesuatu seperti alat, lingkungan, dan segala bentuk kegiatan yang dikondisikan untuk menambah pengetahuan, mengubah sikap atau menanamkan keterampilan pada setiap orang yang memanfaatkannya." (Sanjaya, 2012)

Selanjutnya, untuk memastikan kebenaran dugaan tersebut, peneliti melakukan observasi melalui wawancara dengan salah dua peserta didik juga salah dua pendidik bersangkutan. Keempatnya senada mengatakan bahwa tidak selalu proses belajar dan pembelajaran terganggu oleh gawai. Namun, karena tidak adanya fasilitas yang secara khusus mewadahi proses belajar dan pembelajaran yang dimaksud, kecenderungan penggunaan gawai lebih mengara kepada mengganggu. Lebih jauh, oleh kedua pendidik disampaikan bahwa hal demikian juga tak terlepas dari kurangnya kemampuan serta pengetahuan peserta didik dalam mengatur waktu penggunaan gawai di lingkungan sekolah yang tentunya hal ini menjadi pekerjaan rumah bagi pendidik itu sendiri.

Di sisi lain, dunia saat ini tengah dibuat sulit bergerak oleh adanya pandemi Covid19, termasuk di dalamnya Indonesia. Termonitor melalui https://news.google.com/covid19/map?hl=id $\& \mathrm{gl}=\mathrm{ID} \&$ ceid $=\mathrm{ID} \% 3 \mathrm{Aid} \& \mathrm{mid}=\% 2 \mathrm{Fm} \% 2 \mathrm{~F} 0$ 3ryn sebanyak 123.503 orang dinyatakan positif dengan 5.658 di antaranya meninggal (hingga detik penelitian ini dilakukan) membuat proses belajar dan pembelajarn masih dilakukan dalam jaringan (sekolah dari rumah) sejak 19 Maret 2020. Sekaitan dengan itu, media yang saat ini sangat perlu dikembangkan di SMK Pasim Plus Kota Sukabumi adalah media pembelajaran jarak jauh melalui media elektronik berbasis web atau yang lebih dikenal seagai E-Learning. Namun, banyak yang mengira bahwa penerapan E-Learning, terutama yang berbasis web tak mudah dilakukan mengingat pemrograman bukanlah hal yang bisa dipelajari dalam jarak waktu yang singkat. Di sinilah perkembangan teknologi memainkan perannya. Adalah Moodle, merupakan LMS (Learning Management System) berbasis online dan bersifat open source yang telah dikenal secara luas oleh banyak orang jawabannya. Kelengapan fasilitas seperti 1) penyajian materi format file, folder, SCORM, page, buku, dan URL, 2) memiliki fitur kegiatan pembelajaran, seperti: penugasan, kuis, chatting, forum diskusi, feedback, dab web conference, 3) memiliki fitur pendukung kegiatan pembelajaran, seperti: pengelompokan 
peserta didik, pembatasan hak akses, pemantauan progres belajar peserta didik, penilaian, dan pemberian lencana, angat cukup untuk menunjang proses belajar dan pembelajaran jarak jauh.

Oleh sebab hal-hal demikian, perlu kiranya dilakukan penelitian berjudul "Pengembangan E-Learning Berbasis Web di SMK Pasim Plus Kota Sukabumi”.

\section{METODOLOGI PENELITIAN}

Jenis penelitian yang digunakan dalam penelitian ini adalah Research and Development. Penelitian dan pengembangan dapat diartikan sebagai cara ilmiah untuk meneliti, merancang, memproduksi, dan menguji validitas produk yang dihasilkan (Sugiyono, 2015). Dengan mengadopsi model pengembangan Borg \& Gall, langkahlangkah dalam penelitian ini meliputi:

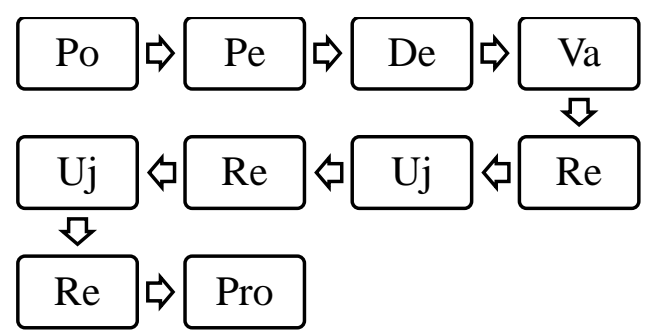

Ket:

Po : Potensi dan Masalah

$\mathrm{Pe} \quad$ : Pengumpulan Data

De : Desain Produk

Va : Validasi Desain

$\mathrm{Re} \quad$ : Revisi Desain

Uj : Uji Coba Produk

Re : Revisi Desain

Uj : Uji Coba Lapangan

Pro : Produksi Masal

Namun, atas kendala waktu, biaya, dan tenaga yang peneliti hadapi, penelitian ini hanya akan dilakukan sampai pada tahap uji coba lapangan.

Metode pengumpulan data yang digunakan ialah kuesioner dan wawancara, dengan menggunakan intstrumen pengumpulan data berupa lembar validasi yang teridiri atas lembar validasi ahli media, lembar validasi ahli materi, dan angket respon peserta didik. Adapun peserta didik yang dimaksud ialah siswa dan siswi SMK Pasim Plus Sukabumi sejumlah 5 orang di uji coba skala kecil dan 20 orang di uji coba skala besar.

\section{HASIL PENELITIAN DAN PEMBAHASAN}

Hasil penelitian ini berupa website eleraning dengan nama domain https://moodle.pasimlearning.com,

dikembangkan melalui moodle yang diunggah ke dalam hosting melalui cPanel. Selanjutnya, https://moodle.pasimlearning.com divalidasi dan diujicobakan kepada ahli materi, ahli media, dan peserta didik kelas XI OTKP 1 SMK Pasim Plus Kota Sukabumi sejumlah 25 orang. Berikut hasilnya:

\section{Validasi Ahli Media}

Validasi kepada ahli media dimaksudkan untuk mengetahui sejauh mana produk yang dikembangkan layak digunakan dari segi media sebagai alat untuk menunjang kegiatan belajar dan pembelajaran. Berikut hal yang menurut ahli media, dalam hal ini Bapak Arif Yudianto, M. Pd, perlu diperbaiki dalam https://moodle.pasimlearning.com: 
Gambar 1 Tampilan Website Sebelum

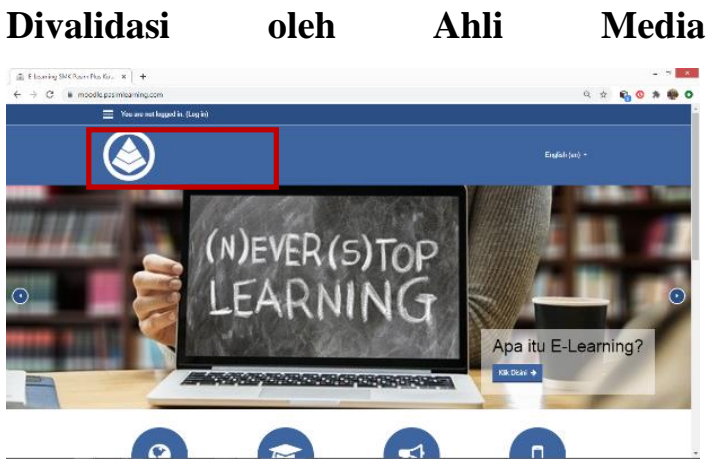

Menurutnya, ada bagian header akan lebih baik jika di samping logo ditambahkan keterangan judul website agar siapapun yang baru pertama kali berkunjung ke website ini dapat langsung mengenali dan memhami identitas serta kegunaan utama dari website. Berikut tampilan terbaru website setelah dilakukan perbaikan:

\section{Gambar 2 Tampilan Website Setelah} Divalidasi oleh Ahli Media

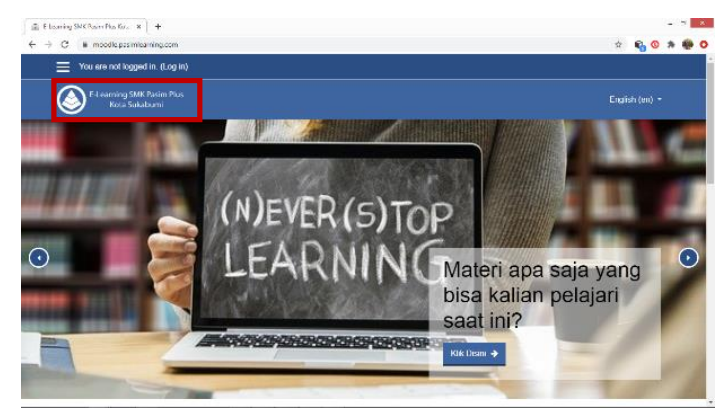

Beberapa aspek yang ditinjau oleh ahli media meliputi: interaktifitas dan software pendukung dari segi pemanfaatan softwrae, serta layout, navigasi, animasi, media, huruf dan warna dari segi tampilan komunikasi visual. Penilaian akhir dari ahli media pada https://moodle.pasimlearning.com ini mencapai rerata 4,4 dari skala 5 yang masuk ke dalam kriteria sangat layak.
Validasi kepada ahli materi dimaksudkan untuk mengetahui sejauh mana materi yang dimuat dalam produk yang dikembangkan sesuai dengan kebutuhan sehingga menjadi layak digunakan dalam kegiatan belajar dan pembelajaran. Berikut hal yang menurut ahli materi, dalam hal ini Aziz Somaduloh selaku guru di SMK Pasim Plus Kota Sukabumi, perlu diperbaiki dalam https://moodle.pasimlearning.com:

\section{Gambar 3 Tampilan Website Sebelum} Divalidasi oleh Ahli Materi

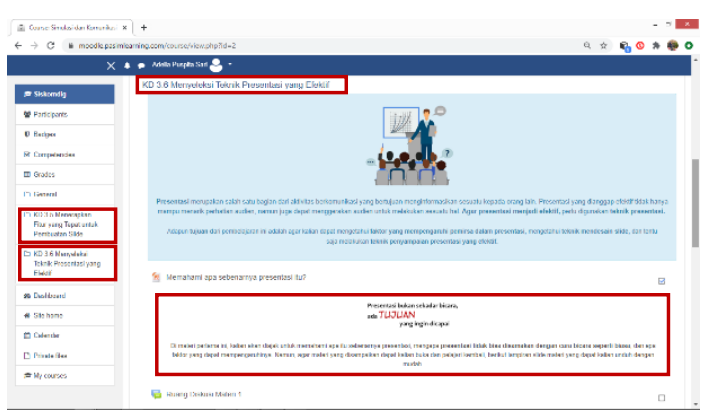

Menurutnya, materi yang dimuat sudah baik dan memenuhi kebutuhan di lapangan. Hanya, ada baiknya Kompetensi Dasar (KD) tidak dijadikan sebagai judul karena hal tersebut dapat membuat peserta didik bingung. Akan lebih baik jika KD disampaikan secara lisan atau tulisan ketika penyampaian materi. Selain itu, kalimat apersepsi di awal materi perlu diberi tanda khusus agar benar-benar dapat menarik perhatian peserta didik untuk membacanya terlebih dahulu. Berikut tampilan terbaru website setelah dilakukan perbaikan:

Gambar 4 Tampilan Website Setelah Divalidasi oleh Ahli Materi

\section{Validasi Ahli Materi}




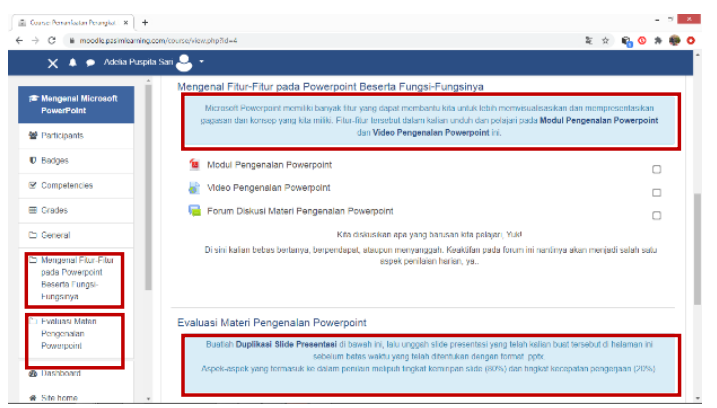

Beberapa aspek yang ditinjau oleh ahli materi meliputi: cakupan, kekinin, kebenaran dan keterbacaan dari segi substansi materi, serta judul, kompetensi dasar, tujuan, materi, contoh soal, evaluasi, penysusun, dan referensi dari segi desain pembelajaran. Penilaian akhir dari ahli materi pada https://moodle.pasimlearning.com ini mencapai rerata 5 dari skala 5 yang masuk ke dalam kriteria sangat layak.

\section{Uji Coba Skala Kecil}

Setelah dilakukan validasi oleh ahli media dan ahli materi, produk yang dikembangkan dianggap telah layak untuk dilakukan uji coba sehingga peneliti bisa mendapatkan respon dan masukan langsung dari peserta didik yang nantinya akan menjadi pengguna https://moodle.pasimlearning.com ini. Uji coba dibagi menjadi dua tahap. Tahap pertama melibatkan peserta didik dalam skala kecil, tahap kedua melibatkan peserta didik dalam skala yang lebih besar. Uji coba skala kecil ini dilakukan oleh 5 orang peserta didik kelas XI OTKP 1 SMK Pasim Plus Kota Sukabumi yang dipilih secara acak. Penilaian akhir dari respon angket yang diberikan kepada 5 orang peserta didik menunjukkan rerata 4,1 dari skala 5 yang masuk ke dalam kriteria layak. Adapun masukan yang peneliti dapati dari uji coba skala kecil ini berupa perbaikan tautan unduh materi yang dirasa kurang kentara sehingga peserta didik kesulitan mencarinya.

\section{Gambar 5 Tampilan Tautan Unduh}

\section{Materi Website}

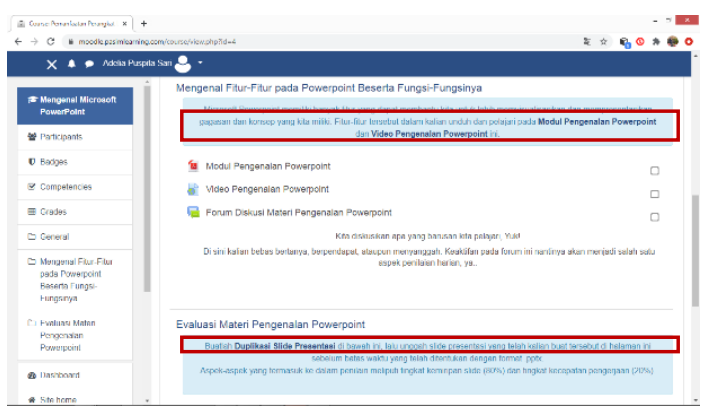

\section{Uji Coba Skala Besar}

Setelah dilakukan perbaikan berdasarakan masukan dan saran dari uji coba skala kecil, yaitu perbaikan tautan unduh materi agar dapar dengan mudah disadari oleh pengguna, dilakukan uji coba tahap kedua dengan jumlah partisipan sebanyak 20 orang peserta didik kelas XI OTKP 1 SMK Pasim Plus Kota Sukabumi yang dipilih secara acak. Penilaian akhir dari respon angket yang diberikan kepada 30 orang peserta didik menunjukkan rerata 4,6 dari skala 5 yang masuk ke dalam kriteria sangat layak.

\section{Kesimpulan}

Berdasarkan temuan dan pembahasan pada pelaksanaan penelitian dan pengembangan e-learning berbantuan moodle di SMK Pasim Plus Kota Sukabumi, dapat ditarik kesimpulan sebagai berikut:

1. Produk hasil penelitian dan pengembangan berupa website e-learning yang dapat diakses melalui domain https://moodle.pasimlearning.com/. 
2. Dari kesepuluh langkah pengembangan Borg \& Gall, penelitian ini hanya dapat dilakukan sampai pada langkah ke delapan (uji coba lapangan) karena adanya kendala waktu, tenaga, dan biaya yang dihadapi oleh peneliti.

3. Hasil akhir penilaian pada produk yang dikembangkan menunjukkan rerata 4,4 dari skala 5 (Sangat Layak) dari ahli media, rerata 5 dari skala 5 (Sangat Layak) dari ahli materi, dan rerata 4,1 dari skala 5 (Layak) dari 5 peserta didik uji coba kecil, serta rerata 4,6 dari skala 5 (Sangat Layak) dari 20 peserta didik uji coba besar.

\section{Daftar Pustaka}

Astuti, Waluya, S. B., \& Asikin, M.

(2019). Strategi Pembelajan Dalam

Menghadapi Tantangan Era

Revolusi 4.0. Seminar Nasional

Pascasarjana 2019, 51-62.

https://proceeding.unnes.ac.id/index.

php/snpasca/article/view/327

Prasetyo, B., \& Trisyanti, D. (2019).

REVOLUSI INDUSTRI 4.0 DAN

TANTANGAN PERUBAHAN

SOSIAL. Prosiding SEMATEKSOS

3 "Strategi Pembangunan Nasional

MenghadapiRevolusiIndustri 4.0"

REVOLUSI INDUSTRI 4.0, 22-27.

Sanjaya, W. (2012). Media Komunikasi

Pembelajaran. Kencana

Prenadamedia Grup.
Sugiyono. (2015). Metode Penelitian \& Pengembangan. Alfabeta.

Triyono, M. B. (2017). TANTANGAN

REVOLUSI INDUSTRI KE 4 (i4.0)

BAGI PENDIDIKAN VOKASI.

Seminar Nasional Vokasi Dan

Teknologi (SEMNASVOKTEK), 4, $1-5$. 